\title{
Normative data and longitudinal invariance of the Life Engagement Test (LET) in a
} community sample of older adults.

4 Elissa L. Pearson ${ }^{1}$, Tim D. Windsor ${ }^{1}$, Dimity A. Crisp ${ }^{2}$, Peter Butterworth ${ }^{2}$, Pamela D.

5 Pilkington $^{3}, \&$ Kaarin J. Anstey ${ }^{2}$

6 1. Centre for Ageing Studies, Flinders University, Adelaide, South Australia, Australia.

7 2. Centre for Research on Ageing, Health and Wellbeing, the Australian National University,

8 Canberra, Australian Capital Territory, Australia.

9 3. Orygen Youth Health Research Centre, Centre for Youth Mental Health, University of 10 Melbourne, Melbourne, Victoria, Australia.

12 Corresponding author:

13 Elissa Pearson

14 Now at the School of Psychology, Social Work \& Social Policy

15 University of South Australia

16 GPO Box 2471 Adelaide SA, 5001, Australia.

17 Email: Elissa.Pearson@UniSA.edu.au

18 Phone: +6108 83024843

19 Fax: +6108 83022956

22 Word count for the manuscript: 1790. 
Purpose: Interest in evaluating purpose in life as an important component of ageing well is growing; however, investigation into the appropriate measurement of this construct is required. The purpose of this paper was to examine the measurement properties of the Life Engagement Test (LET) and to provide normative data for a non-clinical sample of community-dwelling older adults. Methods: A random sample of 545 adults, aged 55-94 years, completed the LET twice over a 12 month period as part of a larger survey on relocation in later life. Results: Consistent with previous research, participants typically reported high levels of purpose in life. Scores were also observed to vary over the 12-month duration, with, on average, an increase in purpose in life at Time 2. However, tests of longitudinal invariance were inconclusive. Conclusions: Future research is needed to further examine the content validity of the LET, and its factorial invariance over longer measurement intervals, and across different populations including non-residential/aged care settings.

42 List of abbreviations

43 CFI Comparative Fit Index

44 LET Life Engagement Test

45 SEM Structural Equation Modeling

46 RMSEA Root Mean Square Error of Approximation

47 WLSMV Weighted Least Squares Mean and Variance adjusted 


\section{Introduction}

Recent theoretical [1] and empirical [2] perspectives on successful adaptation have identified a sense of purpose in life as a key unifying cognitive process that underlies motivation and guides the allocation of resources in responding to changing life contexts. Maintaining a coherent sense of purpose in the face of changing social roles (e.g., retirement, widowhood) and increasing functional decline is likely to be of particular significance to quality of life for older adults [3]. As interest grows regarding aspects of ageing well [4-5], it is clear a need exists for future studies into how purpose in life is developed and maintained, and its implications for psychological and physical health [1, 6-7]. At present this is problematic due to a lack of consensus regarding measurement. Although the Purpose in Life Test [8] and the Purpose in Life sub-scale of the Psychological Wellbeing Scale [9] have been widely used [3], each of these contain retrospective scale items which can confound an individual's sense of present purpose with their perception of how well historical goals were attained [cf. 10$11]$.

A more recently developed measure, the Life Engagement Test (LET), may advance the measurement of purpose in life through its temporal focus on the present. Scheier et al. [12] developed the LET to provide "an index of purpose in life by assessing the extent to which a person considers his or her activities to be valuable and important” (p. 292). Although initial psychometric testing supported the reliability and validity of the LET across diverse samples [12], we are not aware of studies that have assessed the measurement properties in non-clinical samples of male and female older adults. The purpose of the present research was to provide normative data on the LET from community-dwelling older adults and to determine whether the LET demonstrates longitudinal factorial invariance over a twelve month measurement interval. Longitudinal studies are fundamental to research on human development [e.g., 13], and tests of invariance provide a formal means of determining 
whether measurement properties are consistent over time. The present study provides initial data regarding the appropriateness of the LET as a means of assessing longitudinal changes in current purpose in life among older adults.

\section{Methods}

\section{Study sample}

The study sample comprised 545 community-dwelling older adults from the Australian Capital Territory (ACT), recruited as part of a larger study examining relocation from the community into a residential retirement facility. Sampling began by randomly selecting 2000 individuals aged 55 and over from the Australian electoral roll. After excluding individuals living in retirement communities $(\mathrm{N}=27)$, the remaining 1973 individuals were mailed a questionnaire and a letter inviting them to participate in the research. A total of 561 participants returned the questionnaire, with 545 valid responses to the Life Engagement Test (27.6\% response rate). Sample characteristics of age, gender, and partner status (see Table 1) were compared with those of the ACT population [14] using Z tests. The sample did not differ significantly from the population in age (in 5-year bands) or gender, although there was a marginally higher proportion of individuals in the sample who were partnered relative to the ACT population (68.7\%) [15].

\section{TABLE 1 ABOUT HERE}

\section{Materials and procedure}

Participants completed the Life Engagement Test at two separate points in time, approximately twelve months apart (represented as T1 and T2), as part of a larger questionnaire regarding psychosocial aspects of ageing well. The LET consists of six Likert type items, shown in Table 2. Possible scores range from 6-30, with higher scores indicating 
a greater sense of purpose in life. Ethics approval was obtained from the Australian National

University Committee for Ethics in Human Research (Protocol \# 2009/041).

98

\section{Data analysis}

Longitudinal invariance of the LET over the twelve month measurement interval was assessed using confirmatory factor analysis. On account of high negative skewness characterising the LET items, it was not appropriate to apply a standard SEM estimator (e.g., Maximum Likelihood) that assumes multivariate normality. Consequently, we conducted the analysis using a weighted-least square estimator with a mean and variance adjusted chisquare statistic (WLSMV) in Mplus with the delta parameterization. Scale factors for the latent response variables of the categorical indicators at $\mathrm{T} 2$ were free to be estimated, which equates to the latent response variables not being required to have equal variances over time [16]. WLSMV estimation is appropriate for the analysis of ordered categorical variables [17] and provides a good balance between Type I and Type II error rates in the assessment of factorial invariance with censored ordinal variables [18]. Under WLSMV estimation (with no covariates) treatment of missing data is analogous to pairwise present analysis [16].

To test invariance, we specified a baseline model that included equality constraints over time for factor loadings and item thresholds. This approach was consistent with other studies that have examined the invariance of factors with ordered categorical indicators [19] and is analogous to establishing strong factorial invariance (equivalence of factor loadings and item intercepts), which is typically regarded as a minimum condition for longitudinal modelling using latent factors with continuous indicators in an SEM framework [20].

Modification indices were used to examine possible sources of poor fit in the baseline model [e.g., 21]. Variances for the latent factors were freely estimated, and the factors were allowed to correlate over time. Residuals for all corresponding observed indicator variables (e.g., item 
1 at T1 with item 1 at T2) were allowed to correlate. Model fit was assessed with multiple fit indices, including the $\chi^{2}$, RMSEA, and CFI. Due to the high sensitivity of the $\chi^{2}$ to minor violations of the model, the combined goodness of fit was considered across all three indicators.

\section{Results}

\section{Normative data, reliability, and stability across time}

The initial questionnaire was completed by 545 participants, with 423 returning the follow-up questionnaire (417 valid responses to the LET). Mean scores by item and item-total correlations (at T1) are provided in Table 2. Each item demonstrated a correlation of at least 0.7 with the composite scale score.

\section{TABLE 2 ABOUT HERE}

The scale demonstrated sound internal consistency (Cronbach's $\alpha 0.84$ and 0.82 at T1 and T2 respectively) and stability over time, with scores at $\mathrm{T} 1$ accounting for $50.4 \%$ of the variance at $\mathrm{T} 2(\mathrm{r}=0.71)$. The distribution of scores at both time intervals were negatively skewed, reflecting a ceiling effect, such that a majority of older adults in this sample scored toward the upper limit of the scale (T1: skew -1.01, SE 0.11; T2: skew -0.75, SE 0.12). Normative data for this sample at the scale level (by age group, gender, and education level; and across time) are provided in Table 3. At both time points, most participants reported a high level of purpose in life, with scores showing a small (around 0.1 of a standard deviation) increase from $\mathrm{T} 1$ to $\mathrm{T} 2$. Tobit regression analyses (due to the ceiling effects in the data) using $\mathrm{R}$ version 2.14.0 [22] with the VGAM package [23] were conducted to determine whether age group, gender, or education level were associated with LET scores at T1. Findings revealed no significant associations of LET scores with age group or gender ( $p>.05)$, however there 
was a significant association between education level and LET scores $(\mathrm{p}<.001)$ with the predicted value of scores on the LET 1.46 higher for those with 5 or more years of secondary education, compared to those with less than five years.

\section{TABLE 3 ABOUT HERE}

\section{Factor structure and invariance}

Preliminary analysis of the data (available from the authors upon request) replicated the onefactor structure of the LET obtained by Scheier et al. (2006). Confirmatory factor analysis (described above) was used to test invariance of factor loadings and item thresholds. For the initial baseline model, fit statistics were mixed, with $\chi^{2}$ suggesting poor fit, whereas RMSEA and CFI indicated a reasonably well fitting model $\left(\chi^{2}(69)=194.86, p<.001 ; \mathrm{CFI}=.99\right.$; RMSEA = .06). Modification indices showed that fit could be improved by allowing correlations of residuals for item 2 with item 4, and item 3 with item 5 (see Table 2) within each time point. Making these changes to the model resulted in a significant improvement to fit $\left(\chi^{2}(65)=103.64, p<.001 ; \mathrm{CFI}=1.00 ; \mathrm{RMSEA}=.03 ; \chi^{2} \Delta(4)=113.88, p<.001\right)$. While CFI and RMSEA suggested very good fit, the significant value for $\chi^{2}$ remained indicative of unacceptable fit [24-25]. Standardized regression weights for each item in the final model ranged from .71 to .85 .

\section{Discussion}

To date there has been a paucity of research examining age-appropriate motivating factors among older adults, with much research in the field developed using younger samples. There has also been a lack of well validated measures of constructs associated with psychological wellbeing such as sense of purpose and engagement in life, despite the increasing recognition by researchers and policy makers that these factors are integral to ensuring individual and 
social health in ageing societies $[1,12,26-27]$. The present study provides the first longitudinal evaluation of the measurement properties of the LET. Our results pertaining to longitudinal invariance of the LET were inconclusive. On the one hand, alternative fit indices supported the tenability of the model that specified equivalence of factor loadings and item thresholds over the study interval. On the other, the significance of $\chi^{2}$ in the context of our moderate sample size implied poor model fit [28]. Further studies incorporating large sample sizes, and multiple repeated assessments, are needed to better establish the measurement properties of the LET in older samples.

Descriptive analyses indicated that mean LET scores for this sample were generally high, consistent with the findings of Scheier et al. [6], who reported a mean score of 24.9 (SD = 3.4) in a community sample of women aged 60-69. Thus the data provide support for the retention of a strong sense of purpose in life for community-dwelling older populations. The scale may ultimately prove useful for evaluating hypotheses about the effects of significant life events on sense of purpose, such as spousal bereavement, the development of physical impairment or disability, or the transition into retirement $[3 ; 29]$. Nonetheless, in addition to the need for further assessment of measurement invariance, researchers should be mindful of ceiling effects on this scale, and the possible need to use appropriate statistical techniques such as Tobit (censored) regression or hierarchical Tobit models for longitudinal or nested data [see 30].

The present study was limited by the low response rate and generally high level of wellbeing in the sample. Future studies may benefit from sampling more diverse and disadvantaged groups including clinical populations, and those living in aged care settings. Future research is also required to investigate the scale properties over longer intervals, and 
to further evaluate how the construct measured by the LET relates to other psychosocial and

191 health outcomes and biological markers of stress and wellbeing over time [12].

192 
193 Acknowledgements- This research was supported under the Australian Research Council's 194 Linkage Projects funding scheme (project number LP0989584) in partnership with National 195 Seniors Australia and the Illawarra Retirement Trust. The findings and views reported are 196 those of the authors and not necessarily those of the supporting agencies. Tim Windsor is the 197 recipient of an Australian Research Council Future Fellowship (\#FT100100228). Kaarin 198 Anstey (\#1002560) and Peter Butterworth (\#525410) are supported by NHMRC Fellowships. 


\section{References}

1. McKnight, P.E., Kashdan, T.B. (2009). Purpose in life as a system that creates and sustains health and well-being: An integrative, testable theory. Review of General Psychology, 13, 242-251.

2. Chan, C.S., Rhodes, J.E., \& Pérez, J.E. (2011). A prospective study of religiousness and psychological distress among female survivors of Hurricanes Katrina and Rita. American Journal of Community Psychology, doi:10.1007/s10464-011-9445-y

3. Pinquart, M. (2002). Creating and maintaining purpose in life in old age: A metaanalysis. Ageing International Spring, 27, 90-114.

4. Hung, L., Kempen, G.I.J.M., De Vries, N.K. (2010). Cross-cultural comparison between academic and lay views of healthy ageing: A literature review. Aging \& Society, 30, 1373-1391.

5. Charles, S.T., Carstensen, L.L. (2009). Social and Emotional Aging. Annual Review of Psychology, 61, 383-409.

6. Boyle, P.A., Buchman, A.S., Barnes, L.L., Bennett, D.A. (2010). Effect of a purpose in life on risk of incident alzheimer disease and mild cognitive impairment in community-dwelling older persons. Archives of General Psychiatry, 67, 304-310.

7. Naaldenberg, J., Tobi, H., van den Esker, F., Vaandrager, L. (2011). Psychometric properties of the OLQ-13 scale to measure Sense of Coherence in a communitydwelling older population. Health and Quality of Life Outcomes, 9, 37-46.

8. Crumbaugh, J.C., Maholick, L.T. (1964). An experimental study in existentialism: The psychometric approach to Frankl's concept of Noogenic Neurosis. Journal of Clinical Psychology, 20, 200-207.

9. Ryff, C.D., Keyes, C.L.M. (1995). The structure of psychological well-being revisited. Journal of Personality and Social Psychology, 69, 719-727.

10. Karniol, R., Ross, M. (1996). The motivational impact of temporal focus: Thinking about the future and the past. Annual Review of Psychology, 47, 593-620.

11. Pavot, W., Diener, E., Suh, E. (1998). The temporal satisfaction with life scale. Journal of Personality Assessment, 70, 340-354.

12. Scheier, M.F., Wrosch, C., Baum, A., Cohen, S., Martire, L.M., Matthews, K.A., et al. (2006). The life engagement test: Assessing purpose in life. Journal of Behavioural Medicine, 29, 291-298. 
13. Hofer, S.M., Piccinin, A.M. (2010). Toward an integrative science of life-span development and aging. Journal of Gerontology: Psychological Sciences, 65B, 269278.

14. Australian Bureau of Statistics. (2007). Age by Sex, Australian Capital Territory, Census Tables, Census of Population and Housing 2006, cat. no. 2068.0. Retrieved 21 September 2011 from: http://www.censusdata.abs.gov.au/ABSNavigation/download?format=xls\&collection= Census $\&$ period $=2006 \&$ productlabel $=$ Age $\% 20 \mathrm{by} \% 20 \mathrm{Sex} \&$ producttype $=$ Census $\% 20 \mathrm{Ta}$ bles\&method=Place $\% 20 \mathrm{of} \% 20$ Usual $\% 20$ Residence $\&$ areacode $=8$

15. Australian Bureau of Statistics. (2007). Social Marital Status by Age by Sex, Australian Capital Territory, Census Tables, Census of Population and Housing 2006, cat. no. 2068.0. Retrieved 21 September 2011 from http://www.censusdata.abs.gov.au/ABSNavigation/download?format=xls\&collection= Census\&period $=2006 \&$ productlabel $=$ Social $\% 20$ Marital $\% 20$ Status $\% 20$ by $\% 20 \mathrm{Age} \% 20$ by $\% 20$ Sex \&producttype=Census $\% 20$ Tables\&method=Place $\% 20$ of $\% 20$ Usual $\% 20$ Resi dence\&areacode $=81$

16. Muthén, L.K., Muthén, B.O. (2007). Mplus User's Guide (4 ${ }^{\text {th }}$ ed.). Los Angeles, CA: Muthen \& Muthen.

17. Millsap, R.E., Yun-Tein, J. (2004). Assessing factorial invariance in orderedcategorical measures. Multivariate Behavioral Research, 39, 479-515.

18. Koziol, N.A. (2010). Evaluating measurement invariance with censored ordinal data: A monte carlo comparison of alternative model estimators and scales of measurement. Unpublished Masters Thesis, University of Nebraska.

19. Theuns, P., Hofmans, J., Mazaheri, M., Van Acker, F., Bernhein, J.L. (2010). Crossnational comparability of the WHOQOL-BREF: A measurement invariance approach. Quality of Life Research, 19, 219-224.

20. Widaman, K.F., Ferrer, E., Conger, R.D. (2010). Factorial invariance within longitudinal structural equation models: Measuring the same construct across time. Child Development Perspectives, 4, 10-18.

21. Muthén, B.O., \& Asparouhov, T. (2002). Latent variable analysis with categorical outcomes: Multiple-group and growth modelling in Mplus. Mplus Web Note: No. 4 Version, December 9, 2002. Retrieved 1 February 2012 from http://www.statmodel.com/examples/webnote.shtml

22. R Development Core Team. (2011). R: A language and environment for statistical computing. http: //www.R-project.org/ 
23. Yee, T.W. (2011). VGAM: Vector Generalized Linear and Additive Models. R Package version 0.8-4. http://CRAN.R-project.org/package=VGAM

24. Kline, R.B. (2011). Principles and practice of structural equation modelling ( $3^{\text {rd }}$ ed.). New York: The Guilford Press.

25. Barrett, P. (2007). Structural equation modelling: Adjudging model fit. Personality and Individual Differences, 42, 815-824.

26. Andrews, K. (2001). National strategy for an ageing Australia: An older Australia, challenges and opportunities for all. Canberra: Commonwealth of Australia.

27. World Health Organization. (2002). Active Ageing: A policy framework. http://whqlibdoc.who.int/hq/2002/WHO_NMH_NPH_02.8.pdf

28. Markland, D. (2007). The golden rule is that there are no golden rules: A commentary on Paul Barrett's recommendations for reporting model fit in structural equation modelling. Personality and Individual Differences, 42, 851-858.

29. Robbins, S.B., Lee, R.M., Wan, T.T.H. (1994). Goal continuity as a mediator of early retirement adjustment: Testing a multidimensional model. Journal of Counselling Psychology, 41, 18-26.

30. Wang, L., Zhang, Z., McArdle, J.J., Salthouse, T.A. (2008). Investigating ceiling effects in longitudinal data analysis. Multivariate Behavioral Research, 43, 476-496. 
286 Table 1 Sample characteristics

\begin{tabular}{|c|c|c|}
\hline$N$ & & $537-545^{\mathrm{a}}$ \\
\hline \multirow[t]{2}{*}{ Age } & Age Range & $55-94$ \\
\hline & Age, M (SD) & $65.19(8.17)$ \\
\hline Gender & Female & $52.1 \%$ \\
\hline \multirow[t]{4}{*}{ Ethnicity } & Caucasian & $73.0 \%$ \\
\hline & Asian & $2.0 \%$ \\
\hline & African-American & $1.1 \%$ \\
\hline & Not specified/Other & $23.9 \%$ \\
\hline \multirow[t]{4}{*}{ Marital status } & Married/Defacto & $73.5 \%$ \\
\hline & Separated/Divorced & $14.4 \%$ \\
\hline & Widowed & $8.3 \%$ \\
\hline & Never married & $3.9 \%$ \\
\hline \multirow[t]{2}{*}{ Employment } & Working full-time & $27.7 \%$ \\
\hline & Fully retired & $52.7 \%$ \\
\hline \multirow[t]{2}{*}{ Education } & $<5$ years secondary school & $37.2 \%$ \\
\hline & $5+$ years secondary school & $62.7 \%$ \\
\hline Home Ownership & Own residence & $90.0 \%$ \\
\hline
\end{tabular}


Table 2 Descriptive statistics for the Life Engagement Test items

\begin{tabular}{|c|c|c|c|c|}
\hline Life Engagement Test Items & $\begin{array}{c}\text { Mean } \\
(S D)\end{array}$ & Min & Max & $\begin{array}{l}\text { Item-Total } \\
\text { Correlation }\end{array}$ \\
\hline 1. *There is not enough purpose in my life* & $\begin{array}{c}3.99 \\
(1.11)\end{array}$ & 1 & 5 & .77 \\
\hline 2. To me, the things I do are all worthwhile & $\begin{array}{c}3.94 \\
(0.90)\end{array}$ & 1 & 5 & .72 \\
\hline 3. *Most of what I do seems trivial and unimportant to me* & $\begin{array}{c}4.11 \\
(0.98)\end{array}$ & 1 & 5 & .74 \\
\hline 4. I value my activities a lot & $\begin{array}{c}4.13 \\
(0.79)\end{array}$ & 1 & 5 & .78 \\
\hline 5. *I don't care very much about the things I do* & $\begin{array}{c}4.28 \\
(0.94)\end{array}$ & 1 & 5 & .77 \\
\hline 6. I have lots of reasons for living & $\begin{array}{c}4.43 \\
(0.86) \\
\end{array}$ & 1 & 5 & .70 \\
\hline
\end{tabular}

Note: The questionnaire read 'Please answer the following questions about yourself indicating the extent to which you agree or disagree with each statement. Response categories were (1) strongly disagree; (2) disagree; (3) neither agree or disagree; (4) agree; and (5) strongly agree. As items 1,3, and 5 (marked with an asterisk) were negatively worded these were reverse scored to calculate the composite LET score and to facilitate comparison of mean scores across items. Thus for all items a higher mean score indicates a higher sense of purpose in life. 
297 Table 3 Descriptive statistics across time, by age, gender and education level

\begin{tabular}{|c|c|c|c|c|}
\hline & \multicolumn{2}{|r|}{$\mathrm{T} 1$} & \multicolumn{2}{|l|}{$\mathrm{T} 2$} \\
\hline & $N$ & LET Mean $(S D)$ & LET Mean $(S D)$ & $N$ \\
\hline Sample & 545 & $24.86(4.16)$ & $25.43(3.79)$ & 417 \\
\hline \multicolumn{5}{|l|}{ Age } \\
\hline $55-64$ & 300 & $24.89(4.21)$ & $25.45(3.81)$ & 229 \\
\hline $65-74$ & 167 & $25.10(4.20)$ & $25.74(3.78)$ & 136 \\
\hline $75+$ & 74 & $24.30(3.85)$ & $24.44(3.68)$ & 50 \\
\hline \multicolumn{5}{|l|}{ Gender } \\
\hline Male & 261 & $24.64(4.20)$ & $25.34(3.66)$ & 203 \\
\hline Female & 284 & $25.07(4.12)$ & $25.50(3.93)$ & 214 \\
\hline \multicolumn{5}{|l|}{ Education } \\
\hline$<5$ years secondary & 202 & $24.02(4.52)$ & $25.01(3.99)$ & 144 \\
\hline $5+$ years secondary & 340 & $25.38(3.85)$ & $25.65(3.66)$ & 271 \\
\hline
\end{tabular}

